\title{
Populated Places and Conspicuous Consumption: High Population Density Predicts Materialism and Preferences for Luxury Goods
}

\author{
Tobias Otterbring ${ }^{1,}$, Lynn K. L. Tan ${ }^{2}, \&$ Michal Folwarczny ${ }^{3}$ \\ ${ }^{1}$ Professor of Marketing, PhD Psychology, Department of Management, University \\ of Agder, Universitetsveien 17, 4630, Kristiansand, Norway. Email: \\ tobias.otterbring@uia.no \\ ${ }^{2}$ PhD Candidate Psychology, School of Social Sciences, Singapore Management \\ University, 90 Stamford Road, 178903 Singapore, Singapore. Email: \\ lynn.tan.2019@phdps.smu.edu.sg \\ ${ }^{3} \mathrm{PhD}$ Candidate Business Administration, Department of Business Administration, \\ Reykjavik University, Menntavegur 1, 101 Reykjavik, Iceland. Email: \\ michalf@tuta.io \\ * Corresponding author
}

Acknowledgement: This research was supported by a grant awarded to the first author from the Aarhus University Research Foundation (Aarhus Universitets Forskningsfond; AUFF). 


\section{Populated Places and Conspicuous Consumption: High Population Density Predicts Materialism and Preferences for Luxury Goods}

Purpose: Population density has been identified as an ecological factor with considerable behavioral implications. The present research aimed to examine whether country-level differences in population density and even the mere perception of more (vs. less) populated places can shift consumers' preferences in the luxury goods domain.

Design/Methodology/Approach: One intuition study and two main studies with a total sample of over 1,700 consumers tested whether country variations in, and experimental manipulations of population density (high vs. low) exerted downstream effects on consumers' self-reported materialism levels, purchase patterns, and preferences for luxury goods.

Findings: Contrary to the lay beliefs expressed by consumers in an intuition study, Study 1 found British consumers to hold more materialistic values and to be more inclined to consume luxury goods than their American counterparts, with the United Kingdom having eight times higher population density than the United States. Study 2 experimentally manipulated consumers' perceptions of population density and revealed that pictorial exposure to high (vs. low) population density cues resulted in more positive (vs. negative) attitudes toward brands perceived as more (vs. less) luxurious, with this effect being driven by more negative attitudes toward brands deemed to be less luxurious.

Originality: The results contribute to the growing stream of literature on population density and indicate that this (geo-) demographic factor can exert important yet counterintuitive effects on consumer behavior.

Keywords: population density; luxury consumption; conspicuous consumption; status signaling; materialism; international marketing. 


\section{INTRODUCTION}

In 2020 , the value of the personal luxury goods market worldwide was $€ 217$ billion (Sabanoglu, 2021). The growth in this market is largely driven by a set of demographic factors (Christodoulides and Michaelidou, 2009; Jiang and Shan, 2018), including cultural aspects (Demangeot et al., 2015; Yim et al., 2014), country characteristics (Boisvert and Ashill, 2018; Guercini and Milanesi, 2017), and an increased share of the population purchasing luxury goods (Shaikh et al., 2017; Silverstein and Fiske, 2003).

The population size of the United Kingdom (UK) is only 20 percent of that of the United States (US); however, the UK share in global luxury goods sales is half that of the US (Deloitte, 2019). Could this be because British consumers are keener on luxury consumption than their American counterparts? To address this question, we conducted an intuition study where we asked 196 people to indicate whether they thought British or American consumers to be more inclined to purchase luxury goods (e.g., "Which consumers spend more disposable income on luxury goods?" 1 = British; $100=$ American; see Appendix for all items). A onesample $t$-test on a 6-item luxury consumption index $(\alpha=.62)$ revealed that the ratings differed significantly from the scale midpoint $(t(195)=15.2, p<.001)$, indicating that American (vs. British) consumers are perceived as keener on luxury consumption $(M=65.44, S D=13.76)$.

In the present research, we challenge this notion by demonstrating that British consumers are in fact more inclined than their American peers to engage in luxury consumption. We argue that this counterintuitive result occurs not despite a 
population-linked difference between these countries but precisely because of such a difference. Specifically, we predict and provide empirical support for the thesis that country-level differences in luxury consumption can be predicted by differential population densities, with such consumption being more likely to occur in geographic areas characterized by a higher (vs. lower) population density. Moreover, we document that these findings not only apply as a function of objectively different population densities; rather, merely perceiving a place as populated positively modifies consumers' luxury-linked attitudes.

Given that the UK and the US are two of the largest luxury markets worldwide (Chattalas and Shukla, 2015) and that pictorial exposure to population density cues is sufficient for our effect to occur, the findings presented herein should have broad and important implications for international marketing and advertising. In the remainder of this article, we use the term conspicuous consumption to denote the act of purchasing and publicly displaying luxurious goods and services to signal status and wealth to others (Griskevicius et al., 2007; Han et al., 2010; Otterbring et al., 2018; Sundie et al., 2011; Veblen, 1899).

\section{THEORETICAL FRAMEWORK}

\section{Conspicuous Consumption: What, Whether, and Why?}

Throughout human history, social status has always been an important goal; simply consider the grandiose, majestic pyramids and palaces that were built for ancient Egyptian Pharaohs and Emperors of Imperial China during their monarchical rule. Still today, we are repeatedly exposed to revving Ferraris and women wearing Chanel, Gucci, and Prada accessories. Hence, it is relevant to understand the 
underlying motives that may guide consumers' tendencies to flaunt material objects to signal status and wealth.

Conspicuous consumption frequently involves purchasing luxury items that can be used to saliently “show off” one's wealth to others (Griskevicius et al., 2010; Otterbring, 2018; Saad, 2007). The demonstration of wealth serves as a proximal goal to engage in conspicuous consumption, but what is the distal and ultimate explanation for this type of behavior? In other words, does conspicuous consumption serve higher-order goals than merely signaling financial assets? According to the Fundamental Motives Framework (Kenrick et al., 2010), conspicuous consumption facilitates the achievement of certain distal life goals, with social status being the most immediate fundamental aspect addressed through this consumption practice.

High social status endows an individual with access to other vital resources, including strengthened social influence and better health, both physically and psychologically (Nelissen and Meijers, 2011; Marmot, 2004; Otterbring, 2021). Conspicuous consumption - a proxy for high social status-facilitates the attainment of other adaptive goals linked to survival and reproduction (Miller, 2009; Penn, 2003; Saad, 2007; Otterbring et al., 2020), such as attracting mates (DeWall and Maner, 2008; Dunn and Searle, 2010; Griskevicius et al., 2007; Townsend and Levy, 1990). The latter is especially true for men because women, on average, prioritize the financial prospects of a potential mate more than men do (Buss, 1989; Li and Kenrick, 2006; Otterbring and Sela, 2020; Valentine et al., 2020). Thus, although conspicuous consumption carries not only high financial 
costs but also social costs in terms of lowered perceptions of warmth, loyalty and maturity inferences (Cannon and Rucker, 2019; Griskevicius et al., 2009), people engage in this type of consumption because the benefits are deemed to outweigh the costs.

\section{Population Density and Conspicuous Consumption}

Several demographic factors are associated with the tendency to display status conspicuously. For instance, materialistic values-a predictor of conspicuous consumption - increase with age (Jiang et al., 2021). Affluence and ethnicity also predict consumers' tendencies to engage in conspicuous consumption (Ryabov, 2016), just as their job position (employer vs. employee), educational level, and gender (Karunanayake, 2020). In the present research, we argue that another largely overlooked (geo-) demographic factor, population density, could also explain some variance in conspicuous consumption.

Population density has been identified as an ecological factor with important behavioral implications (Ellis et al., 2009, Matherly et al., 2018; Sng et al., 2018). As population density increases, so does competition for limited resources (Ellis et al., 2009). Therefore, population density may act as a cue that resources are becoming increasingly scarce (cf. Folwarczny et al., 2021). For instance, living in densely populated areas could be interpreted as education and job opportunities becoming limited or that a consumer's favorite products and services might soon get sold out. As such, when population density increases, acquiring the necessary resources to meet adaptive goals become more challenging (Sng et al., 2018; Sng and Ackerman, 2020). 
Previous research has found that people living in densely populated places are more materialistic than those living in sparsely populated areas. For example, people living in Singapore - a Southeast Asian densely populated urban countryreported having higher materialistic values than their American peers (Li et al., 2011). Higher materialism among Singaporean (vs. American) women also translates into prioritizing earning capacity in a potential mate (Li et al., 2011), suggesting that women raise their expected standards of potential partners and that men need to demonstrate their wealth more through conspicuous consumption in populated places. However, just as population density may increase men's conspicuous consumption, the same purchase pattern could apply to women as well because people tend to choose partners of similar social status and engage in assortative mating (Buss and Barnes, 1986; Kalmijn, 1994). Thus, women may also magnify their attempts to signal status in densely populated places, given that they, too, engage in conspicuous consumption to address mating-relevant challenges (Wang and Griskevicius, 2014).

Based on the above-mentioned rationale, we predict that consumers in more (vs. less) populated places express stronger materialistic values, resulting in increased purchase preferences for conspicuous goods and more positive attitudes toward such pricey possessions. Study 1 compares consumers who live in countries that are characterized by different population densities: the UK and the US. Considering that the UK's population density is eight times higher than that of the US (Ritchie, 2019), we hypothesize - contrary to people's intuition-based beliefs that British consumers are more materialistic than Americans and, thus, more 
motivated to engage in conspicuous consumption. Next, in Study 2, we test whether experimentally manipulated perceptions of population density is sufficient to change consumers' attitudes toward conspicuous goods, such that exposure to cues of high (vs. low) population density increases positive (vs. negative) attitudes toward brands perceived as more (vs. less) conspicuous. Taken together, our work contributes to the growing body of literature highlighting motivational, attitudinal, and behavioral effects of population density (Ellis et al., 2009, Sng et al., 2018; Sng and Ackerman, 2020), with our findings suggesting that this (geo-) demographic factor can exert important downstream effects on consumer behavior and people's lust for luxury.

\section{STUDY 1: COUNTRY-LEVEL DIFFERENCES IN POPULATION DENSITY AND CONSPICUOUS CONSUMPTION}

The primary purpose of Study 1 was to test our key prediction that British consumers express more materialistic values than American consumers due to the higher population density in the UK compared to the US, resulting in a stronger propensity among British (vs. American) consumers to purchase conspicuous goods. In other words, differences in materialism due to population density should mediate the country-conspicuous consumption link. We tested this prediction using validated psychometric scales for materialistic values and self-perceived luxury consumption.

We recruited 1303 participants from the UK and the US through Prolific (797 women, $M_{a g e}=41$ years). After accepting a consent form, participants filled out the 6-item material value scale (Richins, 2004), measuring the degree to which 
people value possessions ( 1 = Disagree Strongly; 5 = Agree Strongly). Participants also filled out the 8-item self-perceived luxury consumption scale (Hudders and Pandelaere, 2012) using a 5-point scale format ( 1 = never; 5 = very often/always $)$. This scale measures how often people indicate choosing luxury products in eight distinct categories (e.g., clothing, cars, watches). Finally, participants provided demographic details, indicated their Prolific IDs, and responded to an attention check.

\section{Results and Discussion}

The dataset contained 0.23 percent missing values. As we had no reason to assume a non-random distribution of these few missing values, we averaged the scales for each participant based on the responses they provided.

Consistent with our theorizing, an independent samples $t$-test on the 6-item material value scale $(\alpha=.83)$ revealed that British consumers were more materialistic than their American counterparts $\left(M_{\text {British }}=3.06, S D=.85 ; M_{\text {American }}=\right.$ 2.93, $S D=.96), t(1301)=2.27, p=.024$, Cohen's $d=.14, C I_{95}$ for $d=[.02, .27]$.

In further support of our conceptualization, a similar analysis on the 8-item self-perceived luxury consumption scale $(\alpha=.88)$ also indicated that British consumers deemed themselves as buying luxury goods more often than American consumers $\left(M_{\text {British }}=2.10, S D=.74 ; M_{\text {American }}=1.90, S D=.71\right), t(1301)=4.34, p$ $<.001$, Cohen's $d=.28, C I_{95}$ for $d=[.15, .40]$. Thus, across two distinct, wellvalidated instruments linked to conspicuous consumption, British consumers scored higher than their American counterparts, despite people believing the reverse (as per our intuition study). Figure 1 depicts the results of these two analyses. 
---Figure 1---

Next, we performed a mediation analysis with the "mediation" package for R (Tingley et al., 2014) to test the prediction that material values drive the differences between British and American consumers in self-perceived luxury consumption. Nonparametric bootstrap confidence intervals were obtained with 50000 simulations. We report unstandardized regression coefficients below. Supporting our key prediction, the mediation model (see Figure 2) was significant, indicating that material values at least in part explain the differences between the two countries in self perceived luxury consumption, Average Causal Mediation Effects $(\mathrm{ACME})=-0.04, p=.031, C I_{95}=[-0.07, .00] ;$ Proportion Mediated $=.18$, $p=.031, C I_{95}=[.02, .38] ;$ Average Direct Effects $(\mathrm{ADE})=-0.17, p<.001, C I_{95}=$ $[-0.25,-0.08] ;$ Total Effect $\left.=-0.20, p<.001, C I_{95}=[-0.29,-0.11]\right)$. Adding consumer gender as a covariate did not change the nature or significance of our results, either in Study 1 or in Study 2; therefore, gender will not be discussed further.

---Figure 2---

\section{STUDY 2: MANIPULATED POPULATION DENSITY AND CONSPICUOUS CONSUMPTION}

Study 1 showed that consumers from a more (vs. less) densely populated country reported higher material values, which in turn drove conspicuous consumption. Admittedly, however, the UK and the US differ on a wide range of other dimensions 
than population density alone, suggesting that the findings from Study 1 were not necessarily a consequence of this factor. Furthermore, while population density was conceptualized as a construct at the national level in Study 1, materialism and conspicuous consumption were both measured at the individual level. To remedy these shortcomings and provide more compelling evidence for our theorizing, Study 2 exposed participants to visual cues of either high or low population density (cf. Matherly et al., 2018; Sng et al., 2018; Sng and Ackerman, 2020) to test whether experimentally manipulated perceptions of population density could also affect attitudes toward brands deemed to differ on the luxury dimension.

A total of 203 Americans were recruited through Prolific (115 women, $M_{\text {age }}$ $=34$ years). Note that the sole inclusion of Americans constitutes a conservative test of our theorizing because US (vs. UK) participants were found to be less materialistic and less prone to purchase conspicuous goods in Study 1. Participants were randomly assigned to either a high or a low population density condition (see Pretests for details), after which they evaluated 20 familiar brands in terms of their perceived prestige, social status, and exclusivity $(0=$ Not at all; $100=$ Very $m u c h)$. These items (prestige, social status, and exclusivity) were combined to create a luxury index $(\alpha=.96)$. Participants also stated their attitudes toward these brands on a single-item scale $(-100=$ Very negative $; 100=$ Very positive $)$. We randomized the order of these tasks (expressing attitudes and evaluating brands) to minimize the influence of order effects on the results. Finally, participants provided demographic information, indicated their Prolific IDs, and replied to an attention check. 


\section{Pretests}

We conducted a pretest to ensure that consumers were sufficiently familiar with the brands used in Study 2. Twenty-five US participants recruited through Prolific stated how familiar they were with 28 brands $(0=$ Not at all familiar; $10=$ Very familiar) and indicated the extent to which they associated these brands with prestige, social status, and exclusivity $(0=$ Not at all; $100=$ Very $m u c h)$. The 20 brands that participants were most familiar with $\left(M_{\text {familiarity }}=7.1, S D=.8\right)$ were selected for inclusion in the main study. This set covered a wide range of brands that differed markedly in perceived prestige $\left(M_{\text {prestige }}=65\right.$, range $\left.=30-96\right)$, status $\left(M_{\text {status }}=67\right.$, range $\left.=36-96\right)$, and exclusivity $\left(M_{\text {exclusivity }}=61\right.$, range $\left.=27-96\right)$.

To confirm that participants assigned to the high (vs. low) population density condition deemed living spaces as more (vs. less) scarce, we conducted a second pretest, in which sixty-two US participants recruited through Prolific watched a 40-second slideshow consisting of eight slides. In the high-population density condition, participants were exposed to images of places that were full of people. Each slide had a short note describing challenges related to overpopulation. In the low-population density condition, participants were instead exposed to images of similar places that depicted underpopulation. After the slideshow, participants were asked to list three challenges that came to their mind when thinking about overpopulation (vs. underpopulation). Participants also filled out a 4-item measure $(\alpha=.92)$ on perceived space scarcity, which served as a manipulation check: There are too many people living on Earth; Cities have too many inhabitants; It becomes increasingly difficult to find quiet spaces; Many 
people compete for living spaces $(1=$ Disagree Strongly; $7=$ Agree Strongly $)$. An independent samples $t$-test on this 4-item index revealed that participants in the high-population density condition perceived living spaces as scarcer than participants in the low-population density condition $\left(M_{\text {high density }}=5.35, S D=1.56\right.$; $\left.M_{\text {low density }}=3.65, S D=2.10\right), t(60)=3.66, p<.001$, Cohen's $d=.94$. Controlling for participants' positive and negative affect did not change the nature or significance of these results (see the Appendix for supplementary analyses). Thus, the manipulation was successful, and the same slideshows were used to manipulate population density in the main study.

\section{Results and Discussion}

To account for the nested structure of our data and the numerous measures per participant, we performed a linear mixed-effects analysis on the relationship between the luxury index, experimental condition (both treated as fixed effects), and their interaction using the "Ime4" package for R (Bates et al., 2015) with brand attitudes as the dependent variable. As random effects, we used intercepts for participants and brands. We added by-brand random slopes for the effects of the experimental condition (we also added by-participant random slopes for the effects of the experimental condition initially, but this random slope had to be removed due to convergence issues; however, both models lead to the same conclusions). Significance was estimated with Satterthwaite's method (Kuznetsova et al., 2017), and visual inspection of residual plots suggested no apparent deviations from homoscedasticity or normality. 
The analysis revealed a significant main effect of experimental condition, with participants in the low population density condition generally reporting more positive attitudes toward brands, $b=16.04, S E=5.24, t=3.06, p=.003$. Moreover, we found a significant main effect of the luxury index, such that participants had more positive attitudes toward brands they deemed more (vs. less) luxurious, $b=$ $.47, S E=.05, t=9.70, p<.001$. Crucially, the predicted interaction effect between experimental condition and the luxury index emerged, $b=-0.20, S E=.05, t=-4.28$, $p<.001$. In the high-density condition, the effect of the luxury index on brand attitudes was different than in the low-density condition. Specifically, participants exposed to high population density cues had more positive (negative) attitudes toward brands they deemed as more (less) luxurious, as reflected by a steeper slope on the luxury index-brand attitudes graph (see Figure 3). Contrary to our prediction, however, this effect was mainly driven by more negative attitudes toward brands deemed to be less luxurious rather than more positive attitudes toward brands deemed to be more luxurious. Table 1 shows the unstandardized coefficients along with their confidence intervals.

---Table 1---

---Figure 3---

\section{GENERAL DISCUSSION}

The present research shows a link between population density and country-level differences in both materialism and conspicuous consumption, with consumers living in geographic areas characterized by a higher (vs. lower) population density 
reporting stronger materialistic values and a greater propensity to choose such luxury goods. Furthermore, our work demonstrates that pictorial exposure to cues of high (vs. low) population density is sufficient to change consumers' attitudes toward brands deemed as more (vs. less) luxurious. Study 1 found British consumers to hold more materialistic values than their American counterparts, with the UK having eight times higher population density than the US. Moreover, British (vs. American) consumers were significantly more inclined to choose conspicuous goods, with this pattern being mediated by their materialism levels. Study 2 experimentally manipulated perceptions of population density through images and revealed that exposure to high (vs. low) population density cues resulted in more favorable (vs. unfavorable) attitudes toward brands perceived as more (vs. less) luxurious, with this effect being driven by more unfavorable attitudes toward brands deemed to be less luxurious.

\section{Implications and Suggestions for Future Research}

Our findings offer several valuable implications for business practice and international marketing. First, the results reported herein indicate that the UK may be a better market for conspicuous consumption than the US when aggregated at the national level due to different population densities, but also that companies offering luxury goods should strategically target regions (e.g., cities, municipalities, counties, and states) characterized by a higher population density.

Second, because pictorial exposure to population density cues is sufficient for our effect to occur, this suggests that the mere perception of a higher population density may alter consumers' luxury-linked attitudes and their purchase preferences 
for conspicuous goods. Specifically, luxury brands may benefit from using subtle population density cues in their communication campaigns and create the perception of populated places in commercials, advertisements, and on in-store signs located in the vicinity of status-signaling goods to persuade consumers into pricey purchases. Thus, our findings should have broad and important implications for luxury-linked marketing and advertising.

However, while the current studies focused on the impact of population density cues on attitudes and purchase patterns toward luxury products and brands, a fruitful avenue for future research is to test whether our findings may be reversed for certain services. For example, reliance on population density cues in promotions of luxury services, such as exotic vacations, may become counterproductive, as consumers may like the loneliness linked to these luxury experiences and value the private nature of such services. Indeed, due to the nature of luxury brand marketing and its associated "marketing upside-down"-approach, luxury brands may lose their affluent appeal when marketing activities are intensified, lowering revenues because luxury goods and services become reduced to ordinary pleasures (Kapferer and Bastien, 2017).

Scholarly work on population density in the consumption domain is extremely scarce. Roering and Block (1976) examined consumers' search behavior depending on population density and found consumers living in more (vs. less) densely populated areas to spend less time searching for information, while also making fewer shopping trips and visiting a smaller number of stores. More recent research has indicated that experimental manipulations of population density can 
alter consumers' brand choices, with consumers exposed to high (vs low) population density cues being more inclined to avoid common brands to signal uniqueness in identity-relevant product categories (Matherly et al., 2018). Our findings align with these latter results, as luxurious brands are commonly characterized by uniqueness and identity relevance (Berger and Health, 2007; Chan et al., 2012). Thus, the results by Matherly et al. (2018) may, at least partially, have been driven by consumers' greater desire to acquire status-signaling goods under conditions of high (vs. low) population density. This interpretation seems plausible given that consumers tend to be particularly prone to engage in conspicuous consumption in public (vs. private) settings when there are others around to impress (Goenka and Thomas, 2020; Griskevicius et al., 2010; Wang et al., 2020).

However, our results contradict related work on social density (i.e., differing levels of crowding), which has demonstrated that people typically assess higher prices and report a greater willingness to pay for products presented in less (vs. more) crowded contexts, with this effect being driven by status-motivated individuals' attempts to associate themselves with people of higher-status (O'Guinn et al., 2015). Future research should try to address these mixed findings and disentangle under which specific circumstances populated places, crowding cues, and public consumption contexts increase or decrease conspicuous consumption. Finally, future scholarly work could examine whether population density cues presented in different sensory modalities (e.g., auditory cues of crowding or heavy traffic; Sng et al., 2017) evoke the same consumption responses as the visual cues 
used in the present research and whether a multisensory integration of such cues induces a stronger striving for status.

\section{Conclusion}

Thorstein Veblen, a renowned American economist and sociologist, once wrote that "[t]he basis on which good repute in any highly organized industrial community ultimately rests is pecuniary strength; and the means of showing pecuniary strength, and so of gaining or retaining a good name are leisure and a conspicuous consumption of goods." In industrialized areas, frequently accompanied by a high population density, it appears to be adaptive for people to flaunt their wealth to achieve a good social standing and reap the benefits that follow from such flashy displays. Our research, based on a total sample of over 1,700 consumers, supports this notion by demonstrating that actual country-level differences in population density and even the mere perception of more (vs. less) populated places can shift consumers' longing for luxury. Specifically, our findings show that population density predicts consumers' purchase patterns and preferences, with instances of high (vs. low) population density increasing materialism levels and purchases of conspicuous goods, while simultaneously resulting in more negative attitudes toward brands perceived to be less luxurious. 


\section{REFERENCES}

Bates, D., Maechler, M., Bolker, B. and Walker, S. (2015), "Fitting linear mixedeffects models using lme4", Journal of Statistical Software, Vol. 67 No. 1, pp. $1-48$.

Berger, J. and Heath, C. (2007), "Where consumers diverge from others: Identity signaling and product domains", Journal of Consumer Research, Vol. 34 No. 2, pp. 121-134.

Boisvert, J. and Ashill, N. J. (2018), "The impact of branding strategies on horizontal and downward line extension of luxury brands", International Marketing Review, Vol. 35 No. 6, pp. 1033-1052.

Buss, D. M. (1989), “Sex differences in human mate preferences: Evolutionary hypotheses tested in 37 cultures", Behavioral and Brain Sciences, Vol. 12 No. 1, pp. 1-14.

Buss, D. M. and Barnes, M. (1986), "Preferences in human mate selection”, Journal of Personality and Social Psychology, Vol. 50 No. 3, pp. 559-570.

Cannon, C. and Rucker, D. D. (2019), "The dark side of luxury: Social costs of luxury consumption", Personality and Social Psychology Bulletin, Vol. 45 No. 5, pp. 767-779.

Chan, C., Berger, J. and Van Boven, L. (2012), "Identifiable but not identical: Combining social identity and uniqueness motives in choice", Journal of Consumer Research, Vol. 39 No. 3, pp. 561-573. 
Chattalas, M. and Shukla, P. (2015), "Impact of value perceptions on luxury purchase intentions: a developed market comparison”, Luxury Research Journal, Vol. 1 No. 1, pp. 40-57.

Christodoulides, G., Michaelidou, N. and Li, C. H. (2009), "Measuring perceived brand luxury: An evaluation of the BLI scale", Journal of Brand Management, Vol. 16 No. 5, pp. 395-405.

Deloitte. (2019). Global powers of luxury goods 2019. Bridging the gap between the old and the new. https://www2.deloitte.com/gr/en/pages/ consumerbusiness/articles/2019-global-powers-of-luxury-goods.html

Demangeot, C., Broderick, A. J., Craig, C. S., Seo, Y., Buchanan-Oliver, M. and Cruz, A. G. B. (2015), "Luxury brand markets as confluences of multiple cultural beliefs", International Marketing Review, Vol. 32 No. 2, pp. 141159.

DeWall, C. N. and Maner, J. K. (2008), "High status men (but not women) capture the eye of the beholder", Evolutionary Psychology, Vol. 6 No. 2, pp. 147470490800600220.

Dunn, M. J. and Searle, R. (2010), "Effect of manipulated prestige-car ownership on both sex attractiveness ratings", British Journal of Psychology, Vol. 101 No. 1 , pp. 69-80.

Ellis, B. J., Figueredo, A. J., Brumbach, B. H. and Schlomer, G. L. (2009), "Fundamental dimensions of environmental risk: The impact of harsh versus unpredictable environments on the evolution and development of life history strategies", Human Nature, Vol. 20 No. 2, pp. 204-268. 
Folwarczny, M., Christensen, J. D., Li, N. P., Sigurdsson, V. and Otterbring, T. (2021), "Crisis communication, anticipated food scarcity, and food preferences: Preregistered evidence of the insurance hypothesis", Food Quality and Preference, 104213.

Goenka, S. and Thomas, M. (2020), "The malleable morality of conspicuous consumption", Journal of Personality and Social Psychology, Vol. 118 No. 3, pp. 562-583.

Griskevicius, V., Tybur, J. M., Gangestad, S. W., Perea, E. F., Shapiro, J. R. and Kenrick, D. T. (2009), “Aggress to impress: Hostility as an evolved contextdependent strategy", Journal of Personality and Social Psychology, Vol. 96 No. 5, pp. 980-994.

Griskevicius, V., Tybur, J. M., Sundie, J. M., Cialdini, R. B., Miller, G. F. and Kenrick, D. T. (2007), "Blatant benevolence and conspicuous consumption: When romantic motives elicit costly displays", Journal of Personality and Social Psychology, Vol. 93 No. 1, pp. 85-102.

Griskevicius, V., Tybur, J. M. and Van den Bergh, B. (2010), "Going green to be seen: status, reputation, and conspicuous conservation", Journal of Personality and Social Psychology, Vol. 98 No. 3, pp. 392-404.

Guercini, S. and Milanesi, M. (2017), "Extreme luxury fashion: business model and internationalization process", International Marketing Review, Vol. 34 No. 3 , pp. 403-424. 
Han, Y. J., Nunes, J. C. and Drèze, X. (2010), “Signaling status with luxury goods: The role of brand prominence", Journal of Marketing, Vol. 74 No. 4, pp. 1530.

Hudders, L. and Pandelaere, M. (2012), “The silver lining of materialism: The impact of luxury consumption on subjective well-being", Journal of Happiness Studies, Vol. 13 No. 3, pp. 411-437.

Jiang, W., Liu, H. and Jiang, J. (2021), "The development of materialism in emerging adulthood: Stability, change, and antecedents", Personality and Social Psychology Bulletin, Vol. 47 No. 2, pp. 293-306.

Jiang, L. and Shan, J. (2018), "Heterogeneity of luxury value perception: a generational comparison in China”, International Marketing Review, Vol. 35 No. 3, pp. 458-474.

Kalmijn, M. (1994), “Assortative mating by cultural and economic occupational status", American Journal of Sociology, Vol. 100 No. 2, pp. 422-452.

Kapferer, J. N. and Bastien, V. (2017), “The specificity of luxury management: Turning marketing upside down", In Advances in Luxury Brand Management (pp. 65-84). Palgrave Macmillan.

Karunanayake, C. (2020), "Socio demographic determinants behind conspicuous consumption of luxury automobiles in Sri Lanka”, Economic Research, Vol. 7 No. 2, pp. 87-113.

Kenrick, D. T., Griskevicius, V., Neuberg, S. L. and Schaller, M. (2010), "Renovating the pyramid of needs: Contemporary extensions built upon 
ancient foundations", Perspectives on Psychological Science, Vol. 5 No. 3, pp. $292-314$.

Kuznetsova, A., Brockhoff, P. B. and Christensen, R. H. (2017), "ImerTest package: Tests in linear mixed effects models", Journal of Statistical Software, Vol. 82 No. 13, pp. 1-26.

Li, N. P. and Kenrick, D. T. (2006), "Sex similarities and differences in preferences for short-term mates: What, whether, and why", Journal of Personality and Social Psychology, Vol. 90 No. 3, pp. 468-489.

Li, N. P., Patel, L., Balliet, D., Tov, W. and Scollon, C. N. (2011), "The incompatibility of materialism and the desire for children: Psychological insights into the fertility discrepancy among modern countries", Social Indicators Research, Vol. 101 No. 3, pp. 391-404.

Marmot, M. (2004). Status syndrome: How your social standing directly affects your health and life expectancy. London: Bloomsbury.

Matherly, T., Arens, Z. G. and Arnold, T. J. (2018), "Big brands, big cities: How the population penalty affects common, identity relevant brands in densely populated areas", International Journal of Research in Marketing, Vol. 35 No. 1, pp. 15-33.

Miller, G. (2009). Spent: Sex, evolution, and consumer behavior. New York: Viking.

Nelissen, R. M. A. and Meijers, M. H. C. (2011), "Social benefits of luxury brands as costly signals of wealth and status”, Evolution and Human Behavior, Vol. 32 No. 5, pp. 343-355. 
O’Guinn, T. C., Tanner, R. J. and Maeng, A. (2015), “Turning to space: Social density, social class, and the value of things in stores", Journal of Consumer Research, Vol. 42 No. 2, pp. 196-213.

Otterbring, T. (2021), "Evolutionary psychology in marketing: Deep, debated, but fancier with fieldwork", Psychology \& Marketing, Vol. 38 No. 2, pp. 229238.

Otterbring, T. (2018), "Healthy or wealthy? Attractive individuals induce sexspecific food preferences", Food Quality and Preference, Vol. 70, pp. 11-20.

Otterbring, T., Ringler, C., Sirianni, N. J. and Gustafsson, A. (2018), "The Abercrombie \& Fitch effect: The impact of physical dominance on male customers' status-signaling consumption”, Journal of Marketing Research, Vol. 55 No. 1, pp. 69-79.

Otterbring, T. and Sela, Y. (2020), "Sexually arousing ads induce sex-specific financial decisions in hungry individuals", Personality and Individual Differences, Vol. 152, pp. 109576.

Otterbring, T., Sundie, J., Li, Y. J. and Hill, S. (2020), “Evolutionary psychological consumer research: Bold, bright, but better with behavior", Journal of Business Research, Vol. 120, pp. 473-484.

Penn, D. J. (2003), “The evolutionary roots of our environmental problems: toward a Darwinian ecology", The Quarterly Review of Biology, Vol. 78 No. 3, pp. 275-301. 
Ritchie, S. (2019), Which countries are most densely populated? Our World in Data. Retrieved from https://ourworldindata.org/most-densely-populatedcountries

Richins, M. L. (2004), “The material values scale: Measurement properties and development of a short form", Journal of Consumer Research, Vol. 31 No. 1, pp. 209-219.

Roering, K. J. and Block, C. E. (1976), "Population density and type of purchase as explanatory variables in consumer information search", Journal of the Academy of Marketing Science, Vol. 4 No. 4, pp. 731-741.

Ryabov, I. (2016), “Conspicuous consumption among Hispanics: Evidence from the consumer expenditure survey", Research in Social Stratification and Mobility, Vol. 44, pp. 68-76.

Saad, G. (2007), The evolutionary bases of consumption. Mahwah, NJ: Lawrence Erlbaum Associates Publishers.

Sabanoglu, T. (2021), Value of the personal luxury goods market worldwide from 1996 to 2020 (in billion euros), Statista. Retrieved from https://www.statista.com/statistics/266503/value-of-the-personal-luxurygoods-market-worldwide/

Shaikh, S., Malik, A., Akram, M. S. and Chakrabarti, R. (2017), "Do luxury brands successfully entice consumers? The role of bandwagon effect", International Marketing Review, Vol. 34 No. 4, pp. 498-513.

Silverstein, M. J. and Fiske, N. (2003), "Luxury for the masses”, Harvard Business Review, Vol. 81 No. 4, pp. 48-59. 
Sng, O. and Ackerman, J. M. (2020), “Too many people, women, men? The psychological effects of population density and sex ratio", Current Opinion in Psychology, Vol. 32, pp. 38-42.

Sng, O., Neuberg, S. L., Varnum, M. E. W. and Kenrick, D. T. (2018), “The behavioral ecology of cultural psychological variation", Psychological Review, Vol. 125 No. 5, pp. 714-743.

Sng, O., Neuberg, S. L., Varnum, M. E. and Kenrick, D. T. (2017)., “The crowded life is a slow life: Population density and life history strategy", Journal of Personality and Social Psychology, Vol. 112 No. 5, pp. 736-754.

Sundie, J. M., Kenrick, D. T., Griskevicius, V., Tybur, J. M., Vohs, K. D. and Beal, D. J. (2011), "Peacocks, Porsches, and Thorstein Veblen: Conspicuous consumption as a sexual signaling system”, Journal of Personality and Social Psychology, 100 No. 4, pp. 664-680.

Thompson, E. R. (2007), “Development and validation of an internationally reliable short-form of the Positive and Negative Affect Schedule (PANAS)", Journal of Cross-Cultural Psychology, Vol. 38 No. 2, pp. 227-242.

Tingley, D., Yamamoto, T., Hirose, K., Keele, L. and Imai, K. (2014), “Mediation: R package for causal mediation analysis", Journal of Statistical Software, Vol. 59 No. 5, pp. 1-38.

Townsend, J. M. and Levy, G. D. (1990), “Effects of potential partners' costume and physical attractiveness on sexuality and partner selection”, The Journal of Psychology, Vol. 124 No. 4, pp. 371-389.

Veblen, T. (1899). The theory of the leisure class. New York, NY: Macmillan. 
Wang, Y. and Griskevicius, V. (2014), “Conspicuous consumption, relationships, and rivals: Women's luxury products as signals to other women", Journal of Consumer Research, Vol. 40 No. 5, pp. 834-854.

Wang, Y., John, D. R. and Griskevicious, V. (2020), "Does the devil wear Prada? Luxury product experiences can affect prosocial behavior", International Journal of Research in Marketing.

Yim, M. Y. C., Sauer, P. L., Williams, J., Lee, S. J. and Macrury, I. (2014), “Drivers of attitudes toward luxury brands", International Marketing Review, Vol. 31 No. 4, pp. 363-389. 
FIGURES
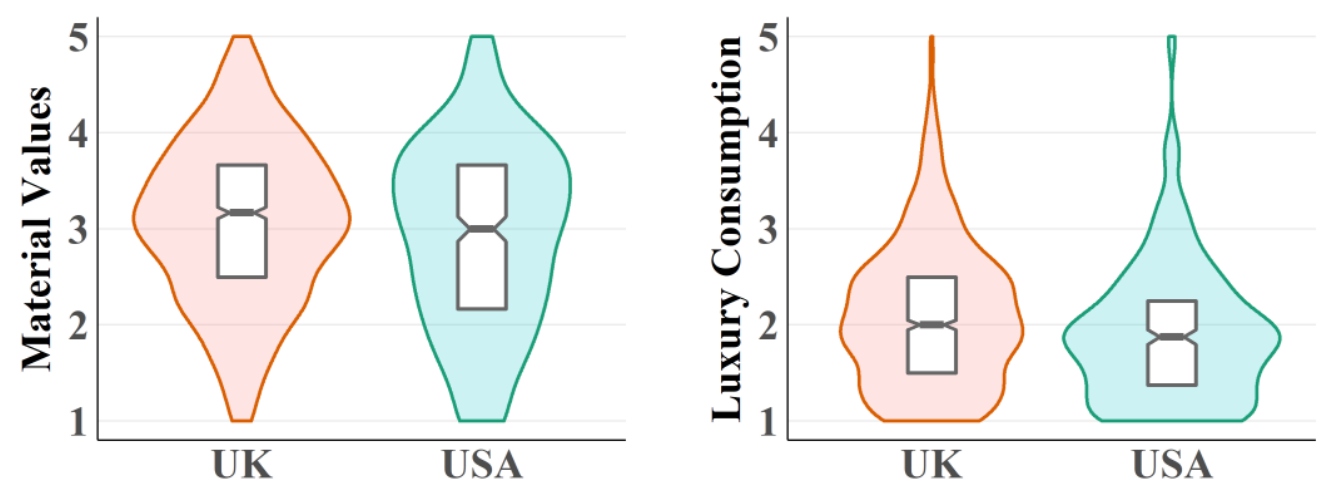

Figure 1: Materialism and Luxury Consumption Across UK and US Consumers

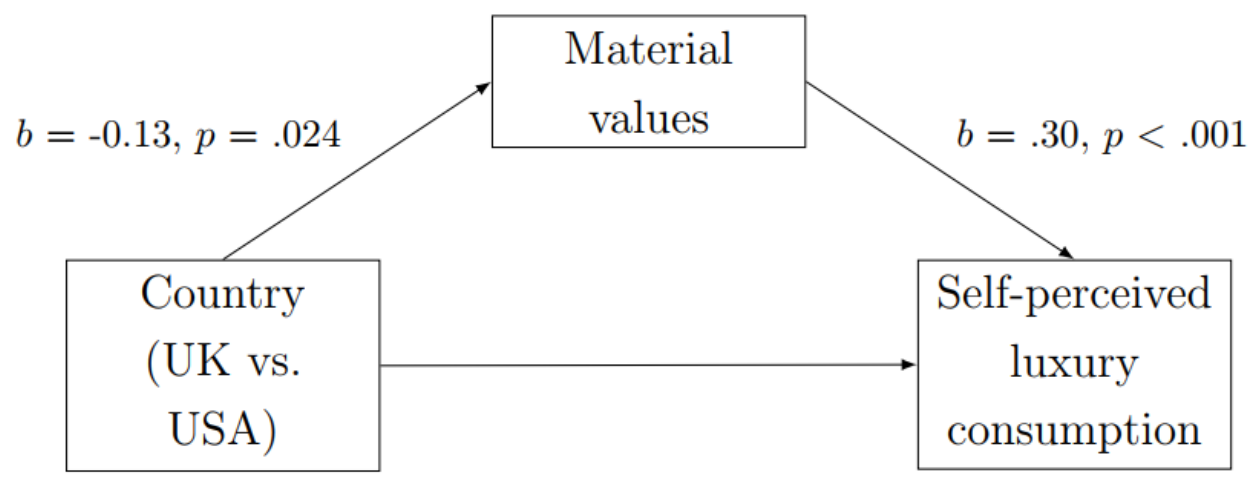

Total effect, $b=-0.20, p<.001$

Direct effect, $b=-0.17, p<.001$

Figure 2: Materialism Mediation of Country Differences in Luxury Consumption

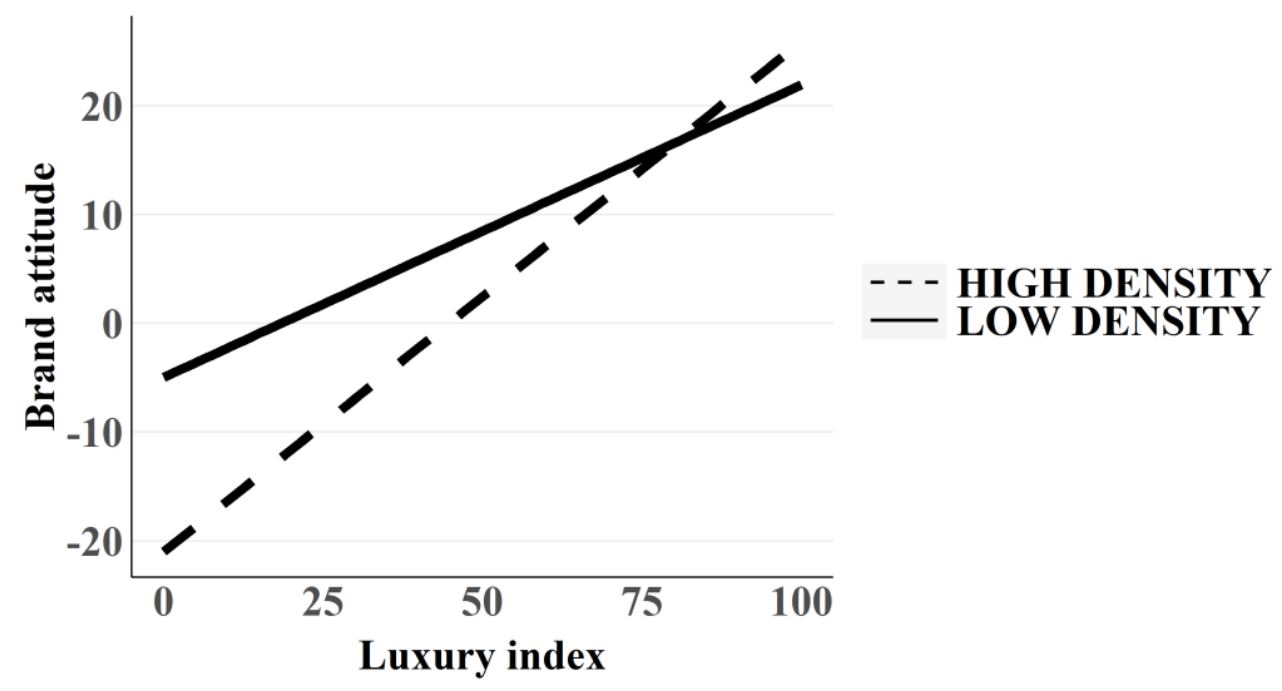

Figure 3: Population Density Effects on Brand Attitudes Toward Luxury Goods 


\section{TABLES}

Table 1: Study 2 results

\begin{tabular}{lc}
\hline & Brand attitude \\
\hline Intercept & $-20.99^{* *}$ \\
Condition (low density) & $-33.56,-8.43]$ \\
& $16.04^{* *}$ \\
Luxury index & {$[5.77,26.32]$} \\
Condition (low density) $\times$ Luxury index & $.47^{* * *}$ \\
& {$[.37, .56]$} \\
Note: & $-0.20^{* * *}$ \\
& $\left.{ }^{*} \mathrm{p}<.0 .29 ;,-0.11\right]$ \\
\hline & Brackets show $\mathrm{p}<.01 ;{ }^{* * *} \mathrm{p}<.001$ \\
\end{tabular}

Table 1: Results With Unstandardized Coefficients and Confidence Intervals 


\section{APPENDIX}

\section{Intuition Study}

\section{Questions on Consumption Habits}

1. Which consumers spend more disposable income on luxury goods?

2. Which consumers buy high-end and expensive cars more often?

3. Which consumers buy high-end and expensive watches more often?

4. Which consumers spend more money on exotic holiday destinations?

5. Which consumers are more materialistic?

6. Which consumers buy more goods/services primarily to impress others?

7. Which consumers spend more money on prestigious wine brands?

8. Which consumers pay more attention to premium brands when shopping?

\section{Additional Data}

1. Age

2. Sex

3. Nationality

4. Attention check: Who is the prime minister or president of your country?

5. Prolific ID

\section{Sample, Design and Procedure}

We recruited 196 native English speakers from different countries through Prolific (119 women, $M_{\text {age }}=32$ years, $S D=11.7$ ). Participants initially accepted a consent form. Next, they indicated their opinions regarding consumption habits of people living in the UK and the US. If they deemed a particular behavior to be more prevalent among British consumers, they had to move a slider to the left. In contrast, if they deemed this behavior to be more prevalent among American consumers, they had to move the slider to the right $(1=$ British; $100=$ American $)$. After answering the eight items, participants provided demographic details, Prolific IDs, and answered the attention check question.

\section{Additional Results}

A factor analysis with varimax rotation on our 8 luxury consumption items suggested a one-factor solution. Items 4 and 7 had unacceptably low loadings of .06 and -0.01 , respectively. Hence, these items were discarded from further analysis. The remaining six items had loadings ranging from .35 to .64 and were combined into a composite luxury consumption index $(\alpha=.62)$.

\section{Study 1}

Material Value Scale (Richins, 2004)

State how much you agree or disagree with the statements below $(1=$ Disagree Stongly; 5 = Agree Strongly)

1. I admire people who own expensive homes, cars, and clothes

2. The things I own say a lot about how well I'm doing in life

3. Buying things gives me a lot of pleasure

4. I like a lot of luxury in my life

5. My life would be better if I owned certain things I don't have

6. I'd be happier if I could afford to buy more things 
Self-Perceived Luxury Consumption (Hudders \& Pandelaere, 2012)

How often do you choose luxurious brands in each product category? $(1=$ never; 5 = very often/always)

1. Clothing

2. Food

3. Cars

4. Watches

5. Wine and Champagne

6. Accessories

7. Home decoration

8. Travel

\section{Additional Data}

1. Age

2. Sex

3. Attention check: Who is the prime minister or president of your country?

4. Prolific ID

\section{Study 2}

\section{Brand Luxury Items}

To what extent is this brand associated with $(0=$ Not at all; $100=$ Very much $)$

1. Prestige

2. Social status

3. Exclusivity

\section{Brand Attitude}

1. What is your attitude toward this brand? $(-100=$ Very negative; $100=$ Very positive)

\section{Additional Data}

1. Age

2. Sex

3. Attention check: What is the name of the city in which you live in?

4. Prolific ID

\section{Additional Results}

Participants in the second pretest also indicated their affect through the short form of the Positive and Negative Affect Schedule (PANAS; 1 = very slightly or not at all; 5 = extremely) (Thompson, 2007). We found no significant differences between population density conditions in positive affect $(p>.63)$. Participants exposed to high population density cues reported higher negative affect $(p=.032)$. Importantly, however, an analysis of covariance (ANCOVA) with population density as the independent variable, negative affect as the covariate, and the manipulation check index as the dependent variable revealed that the effect of population density remained significant ( $p=.003$ ), even after controlling for negative affect $(p>.13)$. Therefore, our manipulation successfully made people believe that living spaces were scarce (vs. abundant), with negative affect unlikely to be the main driver of this effect. 